\title{
ВЛИЯНИЕ РЕЖИМА ДВИЖЕНИЯ АВТОТРАНСПОРТА НА СОДЕРЖАНИЕ СО В ОКРУЖАЮЩЕМ ВОЗДУХЕ
}

Окись углерода считается одним из основных загрязнителей атмосферного воздуха ввиду своей ядовитости [1]. Разрушающее действие СО на растения и неживые объекты с экономической точки зрения незначительно. Критической концентрацией окиси углерода в воздухе, вызывающей раздражающее действие человеческого организма, считается около $\left.10 \mathrm{mz} / \mathrm{M}^{3}{ }^{2}{ }^{2}\right]$. В СССР установлены предельно допустимые концент-

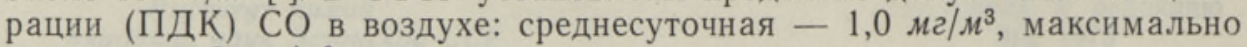
разовая $-3 \mathrm{Mz} / \mathrm{m}^{3}$.

Источники окиси углерода. Главными источниками СО являются естественные процессы, такие как разложение органического вещества, действие вулканов и т. д. Поэтому в воздухе постоянно содержится около $0,1 \mathrm{m2} / \mathrm{M}^{3}$ окиси углерода [ $\left.{ }^{3}\right]$. Из общего количества СО $\left(3,5 \cdot 10^{15}\right.$ 2) в результате прямого действия человека в атмосферу выбрасывается около $2,7 \cdot 10^{14}$ г СО в год [ [4]. Это количество относительно небольшое и не может значительно изменить всемирный баланс $\mathrm{CO}$ в атмосфере Земли. Такое утверждение доказано исследованием арктических льдов, где обнаружено, что за последние 2,5 тыс. лет всемирный уровень СО не увеличился [5]. Весьма вероятно, что выбрасываемая в больших количествах окись углерода все же не накапливается в атмосфере. Механизм ее удаления неизвестен, но можно думать о существовании какого-то биологического «стока», возможно, это почвенные бактерии [ $\left.{ }^{6}\right]$.

Повышенные концентрации окиси углерода, исходящие от действий человека, являясь продуктом неполного сгорания топлива, локализируются в населенных местах. Полнота сгорания топлива выражается отношением двуокиси углерода к окиси углерода в дымовых газах. Это отношение в современных крупных котельнях около $10000: 1$, домашних печах $20: 1$, в выхлопных газах автомобильных двигателей $3: 1$ [7]. Хотя количество бензина, сгораемое в автомобильных двигателях, по отношению к количеству топлива, используемого в стационарных очагах, незначительно, относительно высокое содержание СО в выхлопных газах автомобилей и низкое расположение к земле делает автомобили основными источниками СО в нижнем слое воздуха, необходимом для дыхания.

CO в выхлопных газах автомобилей. Содержание окиси углерода в выхлопных газах карбюраторных двигателей зависит от режима их работы [8]. Исследования Н. Битколова [ $\left.{ }^{9}\right]$ показали, что образование СО при холостом ходе изношенного двигателя может достигнуть $6,6 \%$. При нормальной езде выброс СО зависит от исправности двигателя и их дополнительных систем, марки бензина, скорости движения и колеблется в пределах 0,4-3\%. При замедлении скорости движения эта величина 
увеличивается в 2-3 раза. Кроме того, состав горючей смеси и, таким образом, СО зависит также от температуры, давления и влажности внешнего воздуха $\left[{ }^{10}\right]$. Можно предположить, что любое препятствие на дороге, которое вынуждает резко изменить скорость движения или сделать вре. менную остановку, вызывает и рост концентрации СО в окружающем воздухе.

Результаты наблюдения. Используя ранее выработанный кумулятивный метод определения СО [11], мы исследовали распределение окиси углерода в некоторых характерных узлах автотранспортного движения г. Таллина. Для оценки относительного содержания СО в воздухе были использованы образцы из фильтровальной бумаги, пропитанные раствором $\mathrm{PdCl}_{2}$, которые экспонировались в интересующих нас районах в течении 7 дней. Содержание СО в воздухе пунктов наблюдения определялось по степени потемнения образцов в результате освобождения металлического палладия в реакции

$$
\mathrm{PdCl}_{2}+\mathrm{CO}+\mathrm{H}_{2} \mathrm{O} \longrightarrow \mathrm{Pd}+\mathrm{CO}_{2}+2 \mathrm{HCl}
$$

Потемнение образцов замерялось экстинкционно-регистрирующим прибором ERI-65 фирмы «Карл Цейсс».

Своеобразной зоной, где наблюдается систематическое изменение режима движения, является зона поста ГАИ на шоссейных дорогах. В период с ноября 1972 г. по январь 1973 г. нами были изучены такие зоны на трех главных автомагистралях г. Таллина. Полученные результаты представлены в таблице.

Распределение окиси углерода в зонах постов ГАИ

\begin{tabular}{|c|c|c|c|c|}
\hline \multirow{2}{*}{\multicolumn{2}{|c|}{$\begin{array}{c}\text { Место нахождения } \\
\text { образца }\end{array}$}} & \multicolumn{3}{|c|}{ Относительное потемнение образцов * } \\
\hline & & $\begin{array}{l}\text { Ленинградское } \\
\text { шоссе }\end{array}$ & $\begin{array}{l}\text { Пярнуское } \\
\text { шоссе }\end{array}$ & $\begin{array}{c}\text { Тартуское } \\
\text { шоссе }\end{array}$ \\
\hline Пост & ГАИ & 1,6 & 1,6 & 1,5 \\
\hline Знак & $40 \kappa м / 4$ (из города) & 1,8 & 1,9 & 1,7 \\
\hline Знак & $60 \mathrm{\kappa м} / 4$ (из города) & 1,7 & 1,8 & 1,6 \\
\hline Знак & $40 \kappa м / 4$ (в город) & 1,7 & 1,8 & 1,7 \\
\hline Знак & $60 \kappa м / \psi$ (в город) & 1,6 & 1,7 & 1,6 \\
\hline Зона & скорости $80 \kappa м / ч$ (из города) & 1,0 & 1,0 & 1,0 \\
\hline Зона & скорости $80 \kappa м / 4$ (в город) & 1,0 & 1,0 & 1,0 \\
\hline
\end{tabular}

* Средние результаты всех серий испытаний.

На основе проведенных испытаний составлена схема (рис. 1), представляющая типичную картину относительного рассеивания СО в зонах движения при наличии препятствий.

Средняя скорость движения на шоссейных дорогах равна $90 \kappa м / u$ в основном с равномерной работой двигателя, при приближении к знаку 60 км/ч скорость снижается, нарушается нормальная работа двигателя и это вызывает повышение эмиссии СО. Максимальная концентрация СО обнаружена в области знака $40 \kappa м / u$, где происходит окончательное снижение скорости. Дальнейшее движение происходит с постоянной скоростью и, как видно по рис. 1, концентрация СО у самого поста ГАИ несколько понижается.

Опыты проводились также в районе старого города в период с августа по сентябрь 1973 г. Этот район представлял особый интерес из-за многолюдности на узких улицах, тяжелых условий для движения и стоянок автотранспорта, 


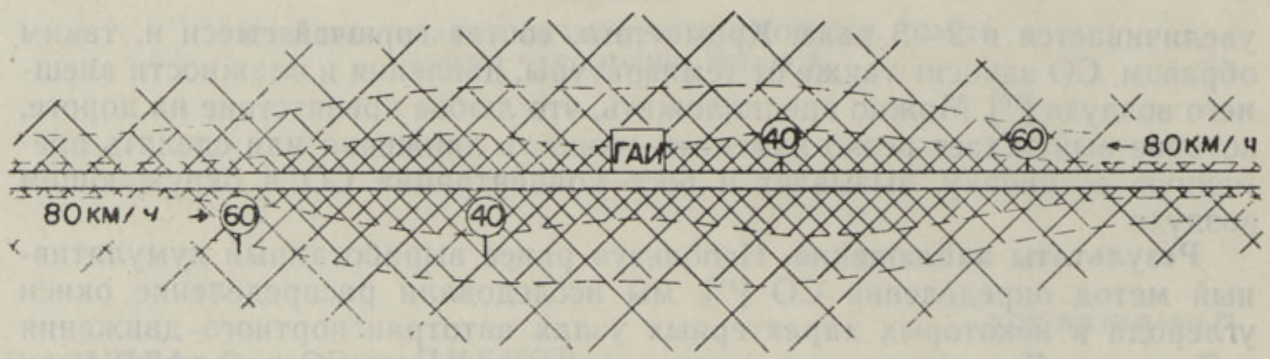

Рис. 1. Рассеивание СО в зонах постов ГАИ на шоссейных дорогах.

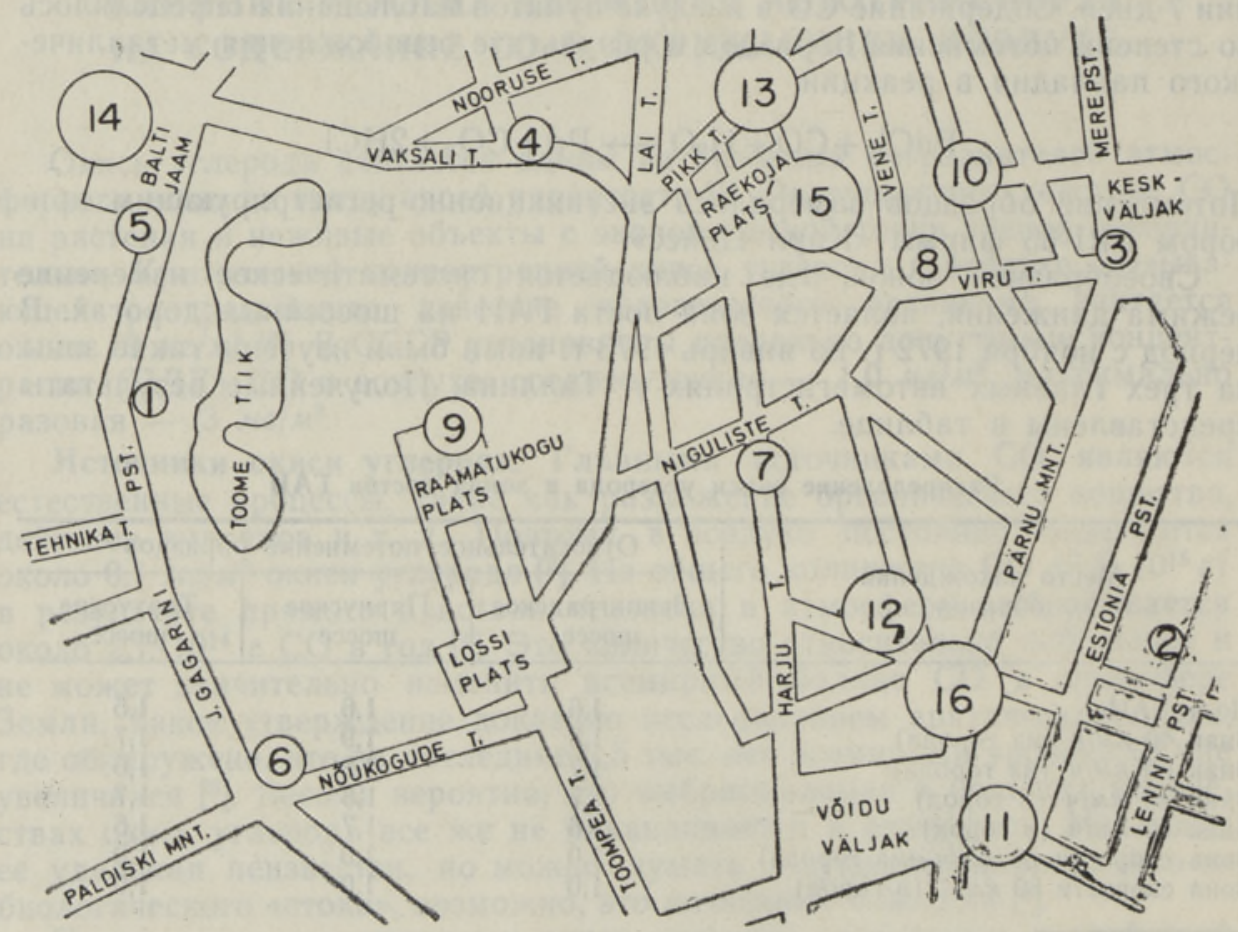

Рис. 2. Относительная концентрация СО в воздухе старой части города Таллина.

Полученные результаты представлены на рис. 2 .

Диаметры кругов в пунктах наблюдения отражают относительную концентрацию окиси углерода в этих точках. Довольно низким является содержание окиси углерода на широких улицах и там, где нет препятствий для движения - бульвары Гагарина (1) и Ленина (2), а также площади (3) и (5). Наивысшие концентрации СО обнаружены на участках с интенсивным движением, но частыми задержками - перекресток Пярну мнт. и Суур-Карья (16), а также в местах скопления автомашин $(14,15,11)$.

На показатели концентрации окиси углерода в воздухе кроме интенсивности и режима движения влияег интенсивность естественного проветривания. Это четко проявляется в анализах, проведенных на узких улицах с домами по обе стороны - ул. Пикк (13), ул. Карья (12), ул. Уус (10), где концентрация СО сравнительно высока. 


\section{Выводы}

1. Нарушение равномерного движения автотранспорта вызывает рост концентрации СО в воздухе в непосредственной близости мест, где происходит систематическое изменение скорости движения.

2. Участки с локально повышенными концентрациями СО в воздухе обнаружены у стационарных постов ГАИ на шоссейных дорогах, на перекрестках улиц, остановках и стоянках автомобилей.

3. В городе с одинаковым характером движения на открытых и хорошо проветриваемых участках концентрация СО примерно в два раза ниже, чем на узких улицах с домами по обе стороны.

\section{Л И Т Е Р А Т Р А}

1 W olf P. C., Environ. Sci. Technol., 5, 213 (1971).

2. B a y H. W., Blurton K. F., Lieb H. C., O s win H. G., Am. Laboratory, 4, 57 $(1972)$

3. L 1 o y d W. G., R ow e D. R., Environ. Sci. Technol., 5, 1133 (1971).

4. Anon., Air-Water Poll. Report, 10, 266 (1972).

5. Anon., Sci. News, 102 (10), 153 (1972).

6. S in g e r S. F., Sci. Amer., 223 (3), 175 (1970).

7. Brockhaus A., Fried richs K. H., Air Pollution Abstr., 3, 3 (1972).

8. S t a r km a n E. S., Combustion-Generated Air Pollution. New York, 1971, p. 205-237.

9. Би тколов Н. З., Очистка выхлопных газов двигателей внутреннего сгорания. M., 1962 , c. 15.

10. Teshirogi $\mathrm{Na}$ oh is a, Ssdaichi $\mathrm{Oz}$ aki, Yoshitada Uchiy a ma, Air Poll. Abstr., 3, 11 (1972).

11. Пикков В., Луйга П., Изв. АН ЭССР, Хим. Геол., 23 (1974).

Ннститут кибернетики

Академии наук Эстонской ССР

\section{Поступила в редакцию} $14 /$ XI 1973

\section{P. LUIGA, Valentina PIKKOV}

\section{AUTODE LIIKLUSREZIIMI MOJU ATMOSFÂARIŌHU CO-SISALDUSELE}

Kumulatiivse määramise meetodil uuriti autode liiklusrežiimi mõju CO suhtelisele jaotusele atmosfääriöhus. Vaatlusi tehti magistraalteedel Riikliku Autoinspektsiooni kontrollpostide ja ristteede piirkonnas, kus sõidukiirust tuleb korduvalt muuta. Leiti CO iseloomulikud jaotused nende piirkondade ōhus.

\section{P. LUIGA, Valentina PIKKOV \\ INFLUENCE OF TRAFFIC CONDITIONS OF THE CONTENT OF CARBON MONOXIDE IN AMBIENT AIR}

Cumulative techniques were used to determine the influence of traffic conditions on the distribution of carbon monoxide in ambient air. Measurements were carried out in the immediate vicinity of highway traffic checkpoints and crossings where a systematic change of speed occurs. Some specific carbon monoxide distribution patterns were stated to exist in these areas. 